\title{
Tails of the unexpected
}

\section{No longer just cellular janitors, cilia are making a clean sweep for biological greatness. Claire Ainsworth explores how they may hold the secret of multicellular development.}

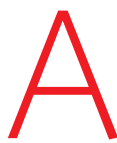

s orgies go, it's pretty wild. Hundreds of whip-wielding participants pile into a seething ball. Stripping naked,

they entwine and embrace, striving to make an intimate connection and consummate the union. If beaten to it by a rival, they move on to another partner until they get lucky. And chances are, it's all carrying on right now in your garden.

But don't call the police or reach for your camcorder yet. These swinging debauchers aren't human, they're single-celled algae called Chlamydomonas, commonly found in soil and water. Affectionately nicknamed 'chlamy' by the scientists who study them, these slimy green organisms and their rumbustious sex lives have a surprising connection with us and how our bodies work. Dissecting that connection is leading researchers to uncover a story that starts more than half-a-billion years ago and ends in modern-day illnesses such as diabetes, cancer and obesity. Along the way it touches the origin of bodies, beauty and symmetry, even helping reveal what makes individuals unique.

The link that brings these together is the whips brandished by our revellers; they're actually flagella that propel chlamy through the environment and are integral to their reproduction. In addition to providing locomotion, this tail-like

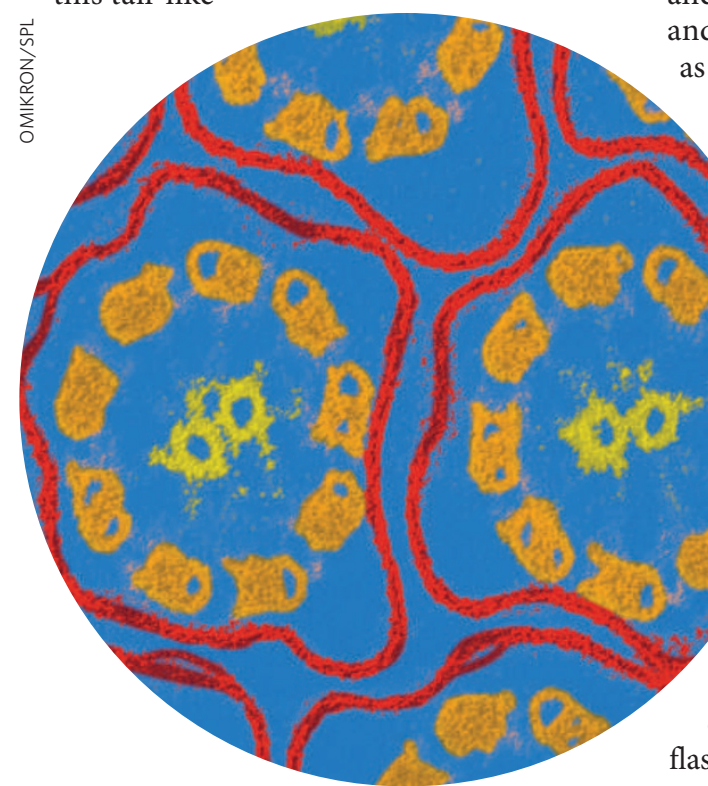

structure acts as an antenna, allowing the cells to sense their environment by detecting signals that indicate the presence of food, predators or mates. When mates meet, their flagella intertwine, sticking together and triggering a cascade of chemical signals that directs the cells to fuse.

This signalling, cooperation and clustering is reminiscent of a momentous biological step. "It's a flirtation with multicellularity as far as I'm concerned," says Bill Snell, a cell biologist and expert on chlamy at the University of Texas Southwestern Medical School in Dallas. About 700 million years ago, single cells clubbed together perhaps using flagella and other similar structures to cooperate and communicate, forming the first multicellular organisms. Now, biologists are realizing that signs of this unicellular ancestry are etched on almost every single cell of our bodies in the form of cilia, shortened versions of flagella that our unicellular ancestors used to flit through Precambrian seas.

As is the case with chlamy, these primitive flagella probably also worked as antennae, receiving signals transmitted by other cells as well as channelling information from the environment. There is growing evidence that cilia are performing similar tasks in our bodies today, sensing and responding to fluid flow and physical stress, helping cells to navigate and move as our bodies develop, and acting as communication conduits.

\section{Stirring things up}

Where they once ignored or overlooked cilia, biologists are now seeing them everywhere and are having to rethink aspects of their fields. "I think it's quite a surprise to developmental biologists," says John Wallingford, a developmental biologist himself at the University of Texas, Austin. And, he adds, "I think a lot of the cell biologists are saying, 'I told you so.'

For a long time, cilia were regarded as lowly janitors, lining our airways and beating in coordination to sweep up dirt and mucus, or wafting eggs down fallopian tubes. True, they had shown flashes of brilliance: single cilia, called kinocilia

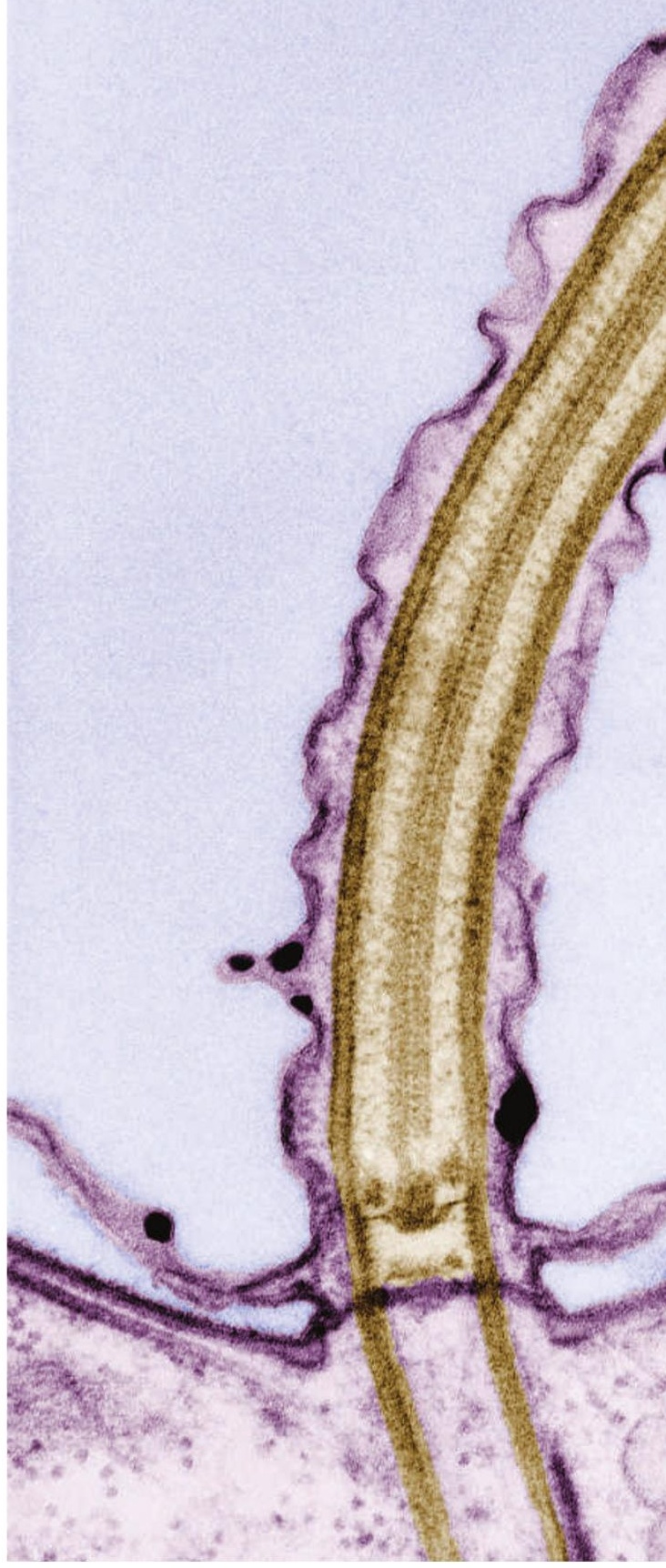

on the hair cells in the inner ear, for example, help us to hear. Cilia play similar roles in sight and smell, but biologists have only recently started to realize that cells carrying cilia are far from exceptions. Almost every cell in the human body carries a cilium, even neurons buried deep in the brain.

The first hint at the primacy of cilia came in 1976, when a Swedish biologist called Björn Afzelius reported the first link between faulty cilia and human disease. Afzelius was studying four infertile men. They were prone to chronic bronchitis, and, bizarrely, three of them had their internal organs placed on the wrong side of their bodies, a rare condition known as situs inversus. Using electron microscopy Afzelius showed that their sperm flagella lacked a key protein component, the dynein arms that help give flagella their kick. The cilia lining 
involved in coordinating body plans. One such set of signals is that of the oddly named hedgehog protein family. Hedgehog was first discovered in fruitflies, and is so named because larvae lacking it have disrupted body plans and are covered in prickles.

\section{From hedgehogs to guinea pigs}

Similar molecules exist in many animals, including mammals, where they coordinate a vast range of cell behaviours. For example, hedgehog signals direct the correct ordering of fingers, the development of lungs and neurons and the spacing of facial features. Stem cells also rely on hedgehog signalling to repair damaged tissue, and several cancers result when it goes wrong. And it seems that it all comes down to cilia. "I think the idea that hedgehog depends on cilia is quite compelling," says Kathryn Anderson, a developmental biologist who studies hedgehog signalling at the SloanKettering Institute in New York.

Anderson and her team stumbled across the link between IFT and hedgehog when they were looking for mutations that disrupted the development of mouse embryos. They found a set of mutants that looked like hedgehog mutants, and were surprised to find that the mutations were in genes coding for IFT proteins, which indicated that intact cilia and IFT were needed for signalling to work 6 . "We weren't looking for cilia, they found us," says Anderson.

Exactly how the system works is unclear. One suggestion is that cilia concentrate signal-ling components together in one place, an idea supported by the findings that hedgehog signalling proteins are localized in cilia. "I think cilia are more complicated than that," says Anderson. Earlier this year, her team showed that hedgehog-signalling components are tethered or released from the internal scaffolding of cilia in response to signalling, pointing to the spatial organization of the cilium being important ${ }^{7}$. And just last month, Matthew Scott and his team at Stanford University School of Medicine, California, showed that key components of the hedgehog -signal reception system move in or out of cilia as part of the signalling process ${ }^{8}$.

Hirokawa has added another twist to the tale. His team found that, as well as generating flow, cilia respond to the signals being wafted to the left-hand side of the embryo. Cilia located on left cells do this by seizing and opening large fatty packets of the signalling molecules needed for creating the asymmetry and
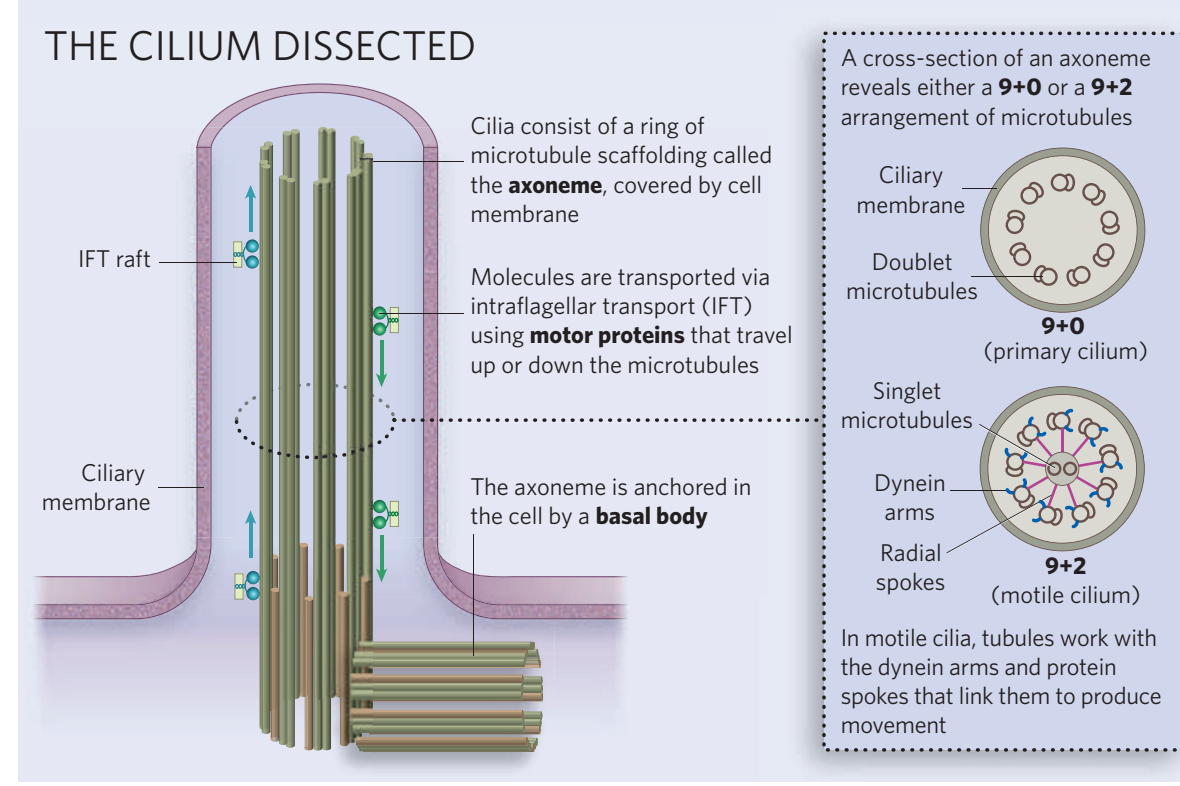

then relaying the signal to their cells. "So the cilium works as a capturing mechanism," says Hirokawa.

But cilia do even more during development: they help individual cells determine where they are within the plane of a sheet of cells. This phenomenon, called planar cell polarity (PCP), ensures, for example, that the hairs in a cat's coat point sleekly in the same direction, or that the hair cells in your inner ear stack the right way to let you hear. It also helps cells to navigate when they move, such as when the neural tube, which forms the developing brain and spinal cord, closes. When PCP is disrupted, the results range from the quirky, such the rosetted fur beloved of guinea-pig fanciers, to the devastating, such as the neural-tube defect spina bifida.

Wallingford was studying PCP and neuraltube defects in Xenopus frogs when he stumbled upon cilia. He and his team had isolated the frog equivalents of two PCPrelated genes found in flies.

When they knocked out the functions of these genes, they found neural-tube defects, as expected. But, oddly, the embryos also had problems consistent with faulty hedgehog signalling 9 . This, and the fact that the genes were expressed at high levels in ciliated skin cells made Wallingford consider cilia. "If you had told me two years ago that I was going to be up to my eyeballs in cilia, I'd have laughed," he says.

\section{A cellular compass}

Looking at the cell's internal skeleton, or cytoskeleton, Wallingford found that the PCPrelated genes controlled the behaviour of actin - the main cytoskeleton protein - during cilium formation and that actin controlled where in the cell the cilium was positioned ${ }^{9}$. This work and that of other scientists supports the idea that the cellular signalling that underlies PCP somehow interacts with the systems that build cilia. The jury is still out on whether, like hedgehog, PCP signals are transduced via cilia, or whether cilia need PCP to form. Wallingford favours the suggestion that the PCP system governs a cilium's position on the cell, denoting its up-down axis, perhaps angling the basal body in the right direction, allowing the cell to determine its orientation.

This compass is also important in making sure cilia, in the airway for example, all beat in the same direction. "When cilia are beating, if there's directed fluid flow across it based on cilia, there has to be a planar polarity there," says Wallingford. His team is now probing possible Guinea-pig fanciers have cilia to thank for rosetted fur. links between PCP and lung diseases 
such as asthma, where cilia go awry. The team has turned to the cilia that line the slimy skins of Xenopus tadpoles - uncannily similar to the lining of our airways - and in unpublished work, they have already identified a suite of new genes involved in generating them.

Although cilia's relationship with cell signalling has come as a surprise to biologists, it may have been signalling that drove them to evolve in the first place. Detlev Arendt and his postdoc Gáspár Jékely at the European Molecular Biology Laboratory in Heidelberg, Germany, were running some bioinformatics studies on IFT proteins when Jékely noticed that they bore a striking resemblance to some of the protein complexes involved in transporting vesicles around the cell ${ }^{10}$. This led them to speculate on the origins of cilia, which have been debated for many years. Lynn Margulis of the University of Massachusetts, Amherst, and her colleagues have suggested that, like mitochondria - the powerhouse of the cell - cilia are derived from bacteria subsumed by other cells. Arendt and Jékely's findings suggest an alternative: that cilia arose from within cells, evolving from an existing signalling system. "It's a good assumption that the original function of the cilium was sensory," says Arendt.

Further analysis indicated that IFT structures and sequences of IFT proteins were related to cellular proteins involved in transporting receptors rather than bacterial proteins ${ }^{10}$. Jékely and Arendt propose that cilia started out as a sensory patch on the surface of a primitive cell.

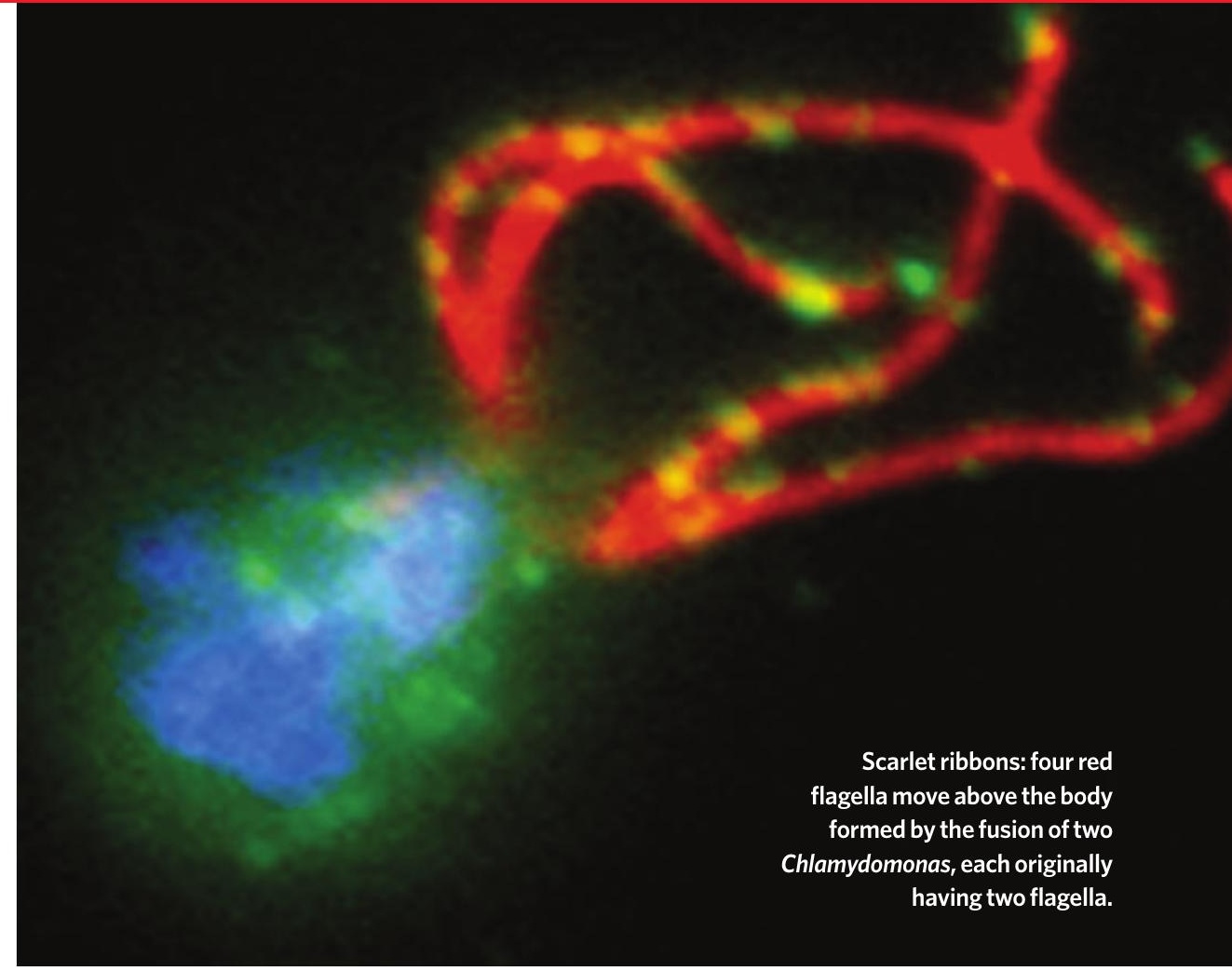

Natural selection would favour patches that bulged out from the surface of the cell, as this would increase the patches' sensitivity.

As signalling between cells probably played a role in the shift to multicellular life, cilia are likely to have helped. Nicole King, an evolutionary biologist at the University of California, Berkeley, has been investigating the role of signalling and the origins of multicellularity by studying choanoflagellates, the closest living single-celled relatives of multicellular animals. "We think that the common ancestor of choanoflagellates and the first animals had a single

\section{Cilia roles in obesity and diabetes}

There is growing evidence that cilia - relatives of the tails that our unicellular ancestors used to move around and sense the environment - are connected with the cellular signalling involved in modern illnesses such as obesity and diabetes.

Ciliopathies, for example, are rare genetic diseases resulting from faulty cilia. The best-known example is Bardet-Biedl syndrome, but a similar condition, Alström syndrome results in earlyonset obesity and diabetes. However, cilia could be related to a number of other conditions. Philip Beales, a geneticist at the Institute of Child Health in London, has probably seen more BardetBiedl cases than anyone else, and thinks that there are at least 25 more ciliopathies to be found. "I am sure we are just seeing the tip of the iceberg," he says.

While screening a medical database for syndromes that had the telltale signs of ciliary defects, Beales and his colleagues recently identified another, Jeune syndrome, caused by defective IFT'11.

Ciliopathy symptoms often vary in severity, and, unlike many inherited diseases, they are not always caused by mutations in a single gene. Some Bardet-Biedl patients, for example, need to carry mutations in three different genes before any symptoms appear ${ }^{12}$. Such conditions are a half-way house between classic single-gene disorders and complex diseases such as obesity that involve many genes, and they may help biologists work out how gene variants interact to cause disease.

They also hint that the collection of variations in cilia-related genes an individual inherits could influence how he or she responds to environmental influences such as a calorierich diet

It's possible that the syndromes represent one end of a range of genetic variations in cilium function, with apparently normal individuals at the other. "Time will tell which [genes] are the most important and to what extent they work with each other or the environment," says Beales.

C.A. flagellum," she says. For the moment, little is known about the choanoflagellate flagellum, but more insights will come from genome projects now underway.

Although choanoflagellates share some signalling systems with multicellular animals, they lack many others. For example, they have fragments of gene sequence that are similar to hedgehog, but, as yet, there is no evidence that they have hedgehog signalling themselves. The full range of signals first shows up in sponges - primitive multicellular animals - suggesting that the raw material of signalling was there in single-celled animals, and expanded upon as multicellularity developed. "It's easy to see how signalling may have been a pre-adaptation to multicellularity and that it might have been co-opted," King says.

It's an intriguing thought that a tiny structure sitting on almost every cell in our bodies links back to a time when cilia were helping cells first get together, and that it still plays a key part in keeping cells together today. As biologists discover yet more roles for cilia, these once obscure organelles seem set for the limelight.

Claire Ainsworth is a freelance writer in Southampton, UK.

1. Afzelius, B. A. Science 193, 317-319 (1976)

2. Nonaka, S. et al. Cell 95, 829-837 (1998).

3. Panzour, G. J. et al. J. Cell Biol. 151, 709-718 (2000)

4. Pan, J. \& Snell, W. J. Mol. Biol. Cell 13, 1417-1426 (2002).

5. Wang, Q., Pan, J. \& Snell, W. J. Cell, 125, 549-562 (2006).

6. Huangfu, D. \& Anderson, K. V. Proc. Natl. Acad. Sci. USA 102, $11325-11330$ (2005)

7. Caspary, T., Larkins, C. E. \& Andersn, K. V. Dev. Cell 12, 767-778 (2007).

8. Rohatgi, R., Milenkovic, L. \& Scott, M. P. Science 317 372-376 (2007).

9. Park, Y.J., Haigo, S. L. \& Wallingford, J. B. Nat. Gen. $\mathbf{3 8}$ 303-311 (2006).

10. Jékely, G. \& Arendt, D. Bioessays 28, 191-198 (2006).

11. Beales, P. L. et al. Nat. Gen. 39, 727-729 (2007).

12. Katsanis, N. et al. Science 293, 2256-2259 (2005). 